\title{
Differences in uptake kinetics of ammonium and nitrate in legumes and cereals
}

\author{
$A$ \\ THEIERTHAM P. RAO, OSAMU ITO and RYOUICHI MATSUNC;A' \\ International Crops Research Institute for the Semi-Arid Tropics (ICRISAT), Patancheru P.O., A.P. \\ 5(12 324. India; 'Present address: Tropical Agriculture Research Center. Ohwashi, Tsukuha, Ibaraki \\ 305. .Japan
}

Key words: ammonium uptake, cereals, kinetics, legumes, ${ }^{19} \mathrm{~N}$, nitrate uptake, translocation

\begin{abstract}
Influx isotherms were obtained for nitrate and ammonium from three legumes. (ajanus cajan (I..) Millsp., (icer arietinum L. and Arachis hypogaea L. and three cereals, Sorghum bicolor (L.) Moench., Pennisetum glaucum L. and Zea mays $\mathrm{L}$. The transition in influx isotherms for both nitrogen sources was found to be within the concentration range $(0.05-2.5 \mathrm{mM})$ tested. There were significant differences in $\mathrm{Km}$ and Vmax for ammonium between legumes and cereals. The difference in the kinetic properties for nitrate uptake between the two groups of plants only beame apparent at the higher concentration tested. Legumes translocated absorbed nitrate and ammonium to shoots more rapidly than cereals. Results show that there are significant differences in uptake and translocation of ammonium and nitrate between legumes and cereals.
\end{abstract}

\section{Introduction}

To characterize nutrient uptake among different species of plants, the total amounts of the particular nutrient taken up by plants during the entire growth period have been often used. To compare any nutrient uptake process per se, however, kinetic parameters on the rate and affinity of membrane transport will be the most suitable indices as they are relatively independent of the dry matter production of the plants. Although nitrogen is a key nutrient for the growth and development of plants, little suceess has been made in inter- (Vin de Dijk et al., 1982) and intraspecific (Pace and Mcclure, 1986) comparison of uptake properties with the kinetic approach, mainly because of the ana-

IC RISAT journal Article No. CP-818 lytical difficulties and poor availability of isotopes $\left({ }^{15} \mathrm{~N}\right.$ and $\left.{ }^{13} \mathrm{~N}\right)$ which enable simple measurement of the element absorbed by plants during a short time period.

It is important to know the kinetic properties of each plant species not only for screening species or genotypes with high absorbing capacity, but also for understanding and predicting the competition for nutrient uptake by plants grown in a mixture with other plant species in natural and agricultural ecosystems. The intercropping of a legume and cereal is widely practised by farmers in the semi-arid tropies (SAT), where water and nutrients are generally limiting. These limited nutrients in soil can be most efficiently exploited by intercropping a combination of crops which are complementary in nutrient uptake.

The present study was initiated to compare 
kinetic parameters of nitrogen uptake and translocation among three legumes and three cercals which are commonly used as component crops in intercropping in the SAT.

\section{Materials and methods}

\section{Plant material and culture conditions}

Three legumes, Pigeonpea (Cajanus cajan (L.) Millsp. var. ICPL 87), Chickpea (Cicer arietinum L. cv. K850) and Groundnut (Arachis hypogaea L. cv. NCAC 17090) and three cereals, Sorghum (Sorghum biocolor (L.) Moench var. CSH5), Millet (Pennisetum glaucum L. var. WC 75) and Maize (Zea mays L. var. Ganga 5) were grown in a greenhouse for a month at an average temperature of $30^{\circ} \mathrm{C}$. Twenty seeds of each plant species were sown in a wooden tray $(150 \mathrm{~mm} \times$ $450 \mathrm{~mm}$ and $120 \mathrm{~mm}$ depth) filled with sand which was thoroughly washed with tap water before the experiment. The plants were regularly supplied with Hoagland nutrient solution modified by Johnson et al. (1957) with $1 / 5$ strength for legumes and 2/5 strength for cereals. Roots were carefully separated from sand with flowing tap water and subjected to uptake rate measurement.

\section{Uptake rate measurement}

Roots detached from a plant were placed in a $50 \mathrm{~mL}$ Erlenmeyer flask with $20 \mathrm{~mL}$ of ${ }^{15} \mathrm{~N}-\mathrm{la}_{-}$ belled $\mathrm{N}$ solution. The flasks were incubated at $30 \pm 2$ ' $\mathrm{C}$ for 2 hours by shaking them vigorously in the dark. The roots of intact plants were placed in a $100 \mathrm{~mL}$ glass tubes containing $75 \mathrm{~mL}$. ${ }^{15} \mathrm{~N}$-labelled $\mathrm{N}$ solution. The tubes were incubated in the greenhousc with full sunlight at $30^{\circ} \mathrm{C}$ for 2 hours. Only ${ }^{15} \mathrm{~N}$-labeled nitrogen salts as ammonium sulfate and potassium nitrate were added into the incubation solution at initial concentrations of $0.05,0.1,0.25,0.5,1.0$ and $2.5 \mathrm{~m} M$ with three replications. The ${ }^{15} \mathrm{~N}$ abundances of nitrate and ammonium were 98 and 99.5 atom $\%$, respectively. After incubation, the plant samples were dried in an oven at $70^{\circ} \mathrm{C}$ for 2 days and then digested with salicylic acid-sulfuric acid mixture and catalyst $\left(\mathrm{K}_{2} \mathrm{SO} / \mathrm{CuSO}_{4} 5 \mathrm{H}_{2} \mathrm{O} /\right.$ Se: $10(0 / 10 / 1)$. The nitrogen content was deter- mined by distillation and titration with $0.005 \mathrm{M}$ sulfuric acid. Nitrogen in the digest was concentrated into a small volume of $0.5 \mathrm{~N} \mathrm{HCl}$ solution by a modified Conway diffusion method (Yoneyama et al., 1975). ${ }^{15} \mathrm{~N}$ abundance in the concentrated solution was analyzed by an emission spectrometer (JASCO N-150).

Kinetic parameters, $\mathrm{Km}$ and Vmax, were calculated using weighed least squares regression analysis of the data according to Michaelis-Menten equations (Epstein, 1972). The results of experiments with detached and intact roots were pooled together as both gave almost identical kinctic parameters. Translocation rates of the absorbed nitrogen were estimated by the ratio of ${ }^{15} \mathrm{~N}$ in the shoots to that in whole plants during the incubation.

\section{Results}

\section{Influx isotherms}

The influx isotherms of nitrate and ammonium are shown in Figure 1. Since the influx rates at $2.5 \mathrm{~m} M$ are far off from the line expected with Michaclis-Menten equation in all cases, there seems to be at least two different uptake patterns within the concentration range tested here. The first component, uptake at low substrate concentrations, is saturable and fits well with MichaelisMenten kinetics. The appropriate modelling for the second component. uptake at higher concentrations of the substrate, is difficult to be drawn due to the limited range of nitrogen concentration in the external medium.

The reciprocal plotting (Lineweaver-Burk plot) of both the external concentration of substrates and influx rates from five sets of data excluding the highest concentration gave straight lines with high correlations $\left(0.82<r^{2}<0.99\right)$ (insets for legumes in Figure 1).

\section{Kinetic parameters}

The $\mathrm{Km}$ and Vmax calculated from the saturable first component (Fig. 1) are shown in Figure 2. The legumes had a higher $\mathrm{Km}$ for ammonium than the cereals. Millet had the lowest $\mathrm{Km}$ among the six plants (0.054 $\left.\mathrm{mol} \mathrm{m}^{3}\right)$. The $\mathrm{Km}$ for nitrate was not very different in the legumes 


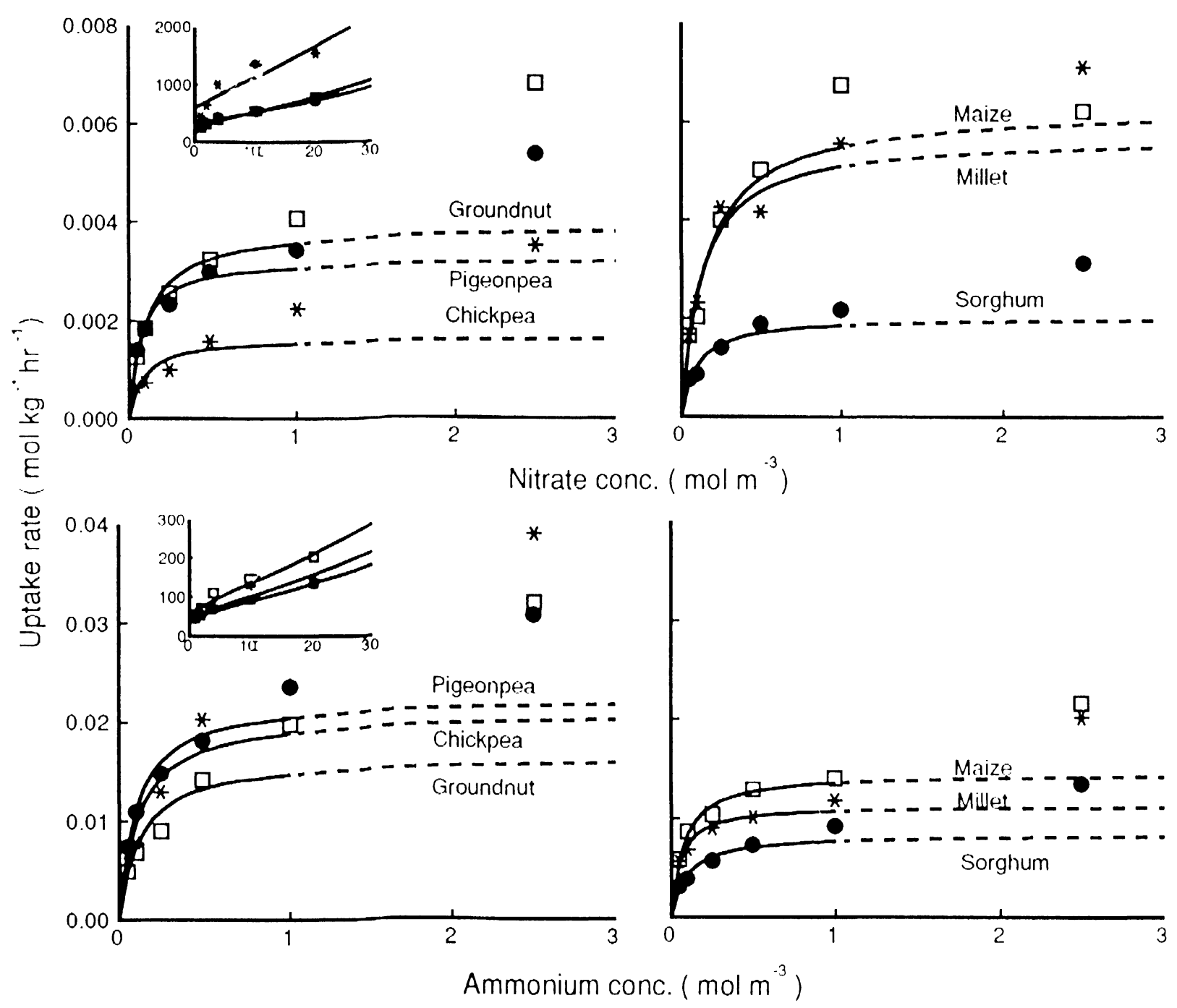

Fig. I. Inllux isotherms of nitrate (top) and ammonium (bottom) for legumes (left) and cereals (right). Insets show LincucalverBurk plots for the influx of nitrate and ammonium for legumes. The lines were estimated with the influx rates at the lower five concentrations.

and cereals tested. Vmax was strikingly higher for ammonium than for nitrate. The Vmax for ammonium was higher for the legumes than for the cereals, whereas no clear trend was found among the species in the Vmax for nitrate. Assuming a lincar relationship for the second component, a $k$ was obtained from the influx rate at $2.5 \mathrm{~m} M$ and the simulated rate at $1.0 \mathrm{~m} M$. The $k$ was higher for ammonium than for nitrate. The legumes had a higher $k$ for both nitrate and ammonium than did the cereals (Fig. 2).

\section{Translocation}

Since differences in the distribution pereentage of $\mathrm{N}$ among the lower five concentrations were not significant, they were averaged. Nitrate was more readily translocited to shoots than am- monium in all plant species (Table 1). For both nitrate and ammonium. legumes had higher distribution percentages to the shoot than cereals, indicating a more rapid translocation in the legumes than in the cereals.

\section{Discussion}

The transition in inllux isotherms was first demonstrated by Epstein (1972) and defined as a dual pattern of ion uptake. The saturable pattern according to the Michaclis-Menten equation was applied to both components. Since Km and Vmax are always lower in the first component than in the second, it was suggested that the first was controlled by a carrier-mediated process and the second by a passive diffusion process. The 

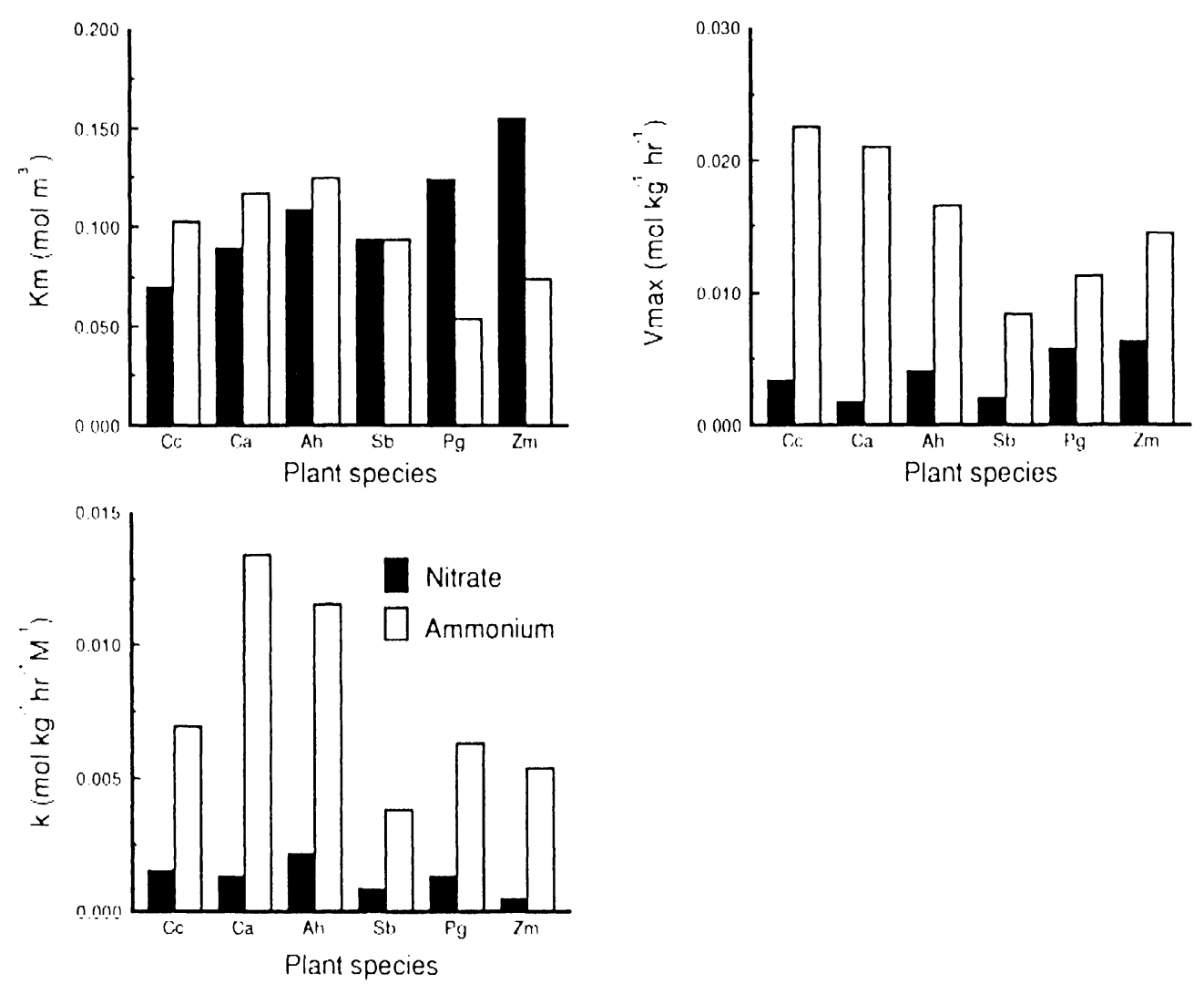

Fig. 2. Kinetic parameters for the uptake of nitrate and ammonium hy legumes and cereals. The Km (mol M ") and Vmax (mol $\mathrm{kg}{ }^{\prime} \mathrm{hr}$ ') were calculated from Lineweaver-Burk plots. The $k$ (mol $\mathrm{kg}{ }^{1} \mathrm{hr}{ }^{\prime} \mathrm{M}$ ') is the slope of the linear line between the influx rate at $2.5 \mathrm{mM}$ and the simulated rate at $1.0 \mathrm{mM}$. Ce-Pigeonpea (Cajamus cajan L.). Ca . Chickpea (Cicer arietinum L..), Ah- (iroundnut (Arachis hypogae'a L.), Sb=Sorghum (Sorghum bicolor I..). Pg-Millet (Pennisetum glancum I..) and 7.m - Maize (Zea may.s L.)

Table l. Percentage distribution of nitrogen translocated to the shoot to nitrogen absorbed by three legumes and three cercals $1^{\prime \prime} \mathrm{N}$ in shoot $/{ }^{\prime \prime} \mathrm{N}$ in whole plants $\times 10(1)$

\begin{tabular}{lll}
\hline Species & \multicolumn{2}{l}{ N sources } \\
\cline { 2 - 3 } & Nitrate & Ammonium \\
\hline Pigeonpea & 51 & 19 \\
Chickpea & 71 & 24 \\
Groundnut & 37 & 19 \\
Sorghum & 20 & 7.1 \\
Millet & 23 & 12 \\
Maisc & 26 & 6.3 \\
Mean & 38 & 1.5 \\
SE & 3.4 & 1.3 \\
CV'; & 20 & 19 \\
I.SD & 10 & 3.7 \\
\hline
\end{tabular}

Each value is an average of five treatments with different $N$ concentrations. Data from the highest concentration $(2.5 \mathrm{~m} M)$ were omitted as the influx and translocation of nitrogen may be driven by a different mechanism at this concentration (see texi). data obtained in the present study are also not compatible with a single saturable component (Fig. 1), again suggesting that the influx isotherms for both nitrate and ammonium should consist of at least two components. The transition point may be somewhere around $1 .() \mathrm{m} M$ in both cases. Rao and Rains (1976) reported that in barley roots, the uptake rate of nitrate was accelerated as the external concentration exceeded $0.5 \mathrm{~m} M$. Approximately the same concentration for the transition point has been reported for potassium with corn (Kochian and Lucas, 1982) and ryegrass (Glass and Dunlop, 1978), and for phosphate with corn (Nandi and Pant, 1984). It should also be noted that this transition in isotherms exists in all six plant species used in this study.

There has been a long debate on the characterization of the second component. A multiphasic model has been proposed for potassium (Nissen, 1989) and phosphate (Singh and Pant, 1982), which can incorporate the present theory 
on ion transport with multistate ion channels. In contrast, Kochian and Lucas (1982) and Vale et al. (1987) indicated that the second phase of potassium uptake could be described with a lincar term, suggesting the existence of two distinct uptake mechanisms. Although the present study does not provide confirmative evidence for the isotherm pattern of the second component of nitrate or ammonium uptake, the assumption of a lincar component for concentrations $>1 \mathrm{~m} M$ to calculate the $k$ is supported by recent results with barley (Siddici et al., $199(0)$ and maize (Pace and McClure, 1986).

Significant differences were found between legumes and cereals in $\mathrm{Km}, \mathrm{Vmax}$ and $k$ for ammonium (Fig. 2). Since ammonium is not a predominant form of nitrogen under the upland conditions where the plants used in this study are commonly cultivated, those differences may not have a practical importance in the ficld. For nitrate, the only clear difference between legumes and cereals was observed in $k$ (Fig. 2). Although $k$ is a tentative index for uptake kinetics at concentrations $>1 \mathrm{~m} M$, the results imply that at the high concentration range nitrate absorption in legumes is at a relative advantage compared to that in cereals. Following the application of ammonical fertilizer, nitrate concentration in the soil solution was maintained above $1 \mathrm{~m} M$ for a few weeks (Ito et al., 1992).

The legumes were also found to be more efficient than cercals in translocating the absorbed nitrogen from root to shoot (Table 1). Especially the translocation rate of nitrate in shickpea was strikingly higher than in other species. This may be partly associated with the highest transpiration rate (data not presented) in this species. Another factor that regulates nitrate translocation may be the distribution of nitrate reductase (NR) within the plant. Since the translocation of ammonium is much slower than that of nitrate (Table 1), differences in translocation between legumes and cereals may be related to the NR activity in the roots. Root tips of Zea mays had a high level of in vitro NR activity (Oaks et al., 1979) and, as a consequence, a high correlation was found between numbers of lateral roots (which should correlate with number of root tips) and nitrate reduction (Pan et al., 1985). In (icer arientinum, however, NR activity was higher in shoots than in roots (Wasnik et al., 1988). The rapid translocation in legumes may be due to the lower conversion of nitrate to ammonium and amino acids in legume roots than in cereal roots.

The present study confirms that influx isotherms for both nitrate and ammonium have a transition at approximately $1 \mathrm{~m} M$, if the first component operating at low concentrations is assumed to be saturable according to MichaelisMenten kinetics. Significant differences in kinetic properties were found between legumes and cercals, implying that the nitrogen utilization may be improved by intercropping a proper combination of crops. Since the nutrient uptake may be influenced not only by kinetic properties but also by root morphological and metabolic traits (Robinson and Rorison, 1983), further comparative studies should be conducted to correlate these interspecific differences with root morphology and activitics.

\section{Acknowledgements}

We extend our sincere thanks to Dr C Johansen and Dr J V D K Kumar Rao for their valuable and critical evaluation of this paper. Our thanks also go to Mrs Y Gayathri Devi for the help of graphic presentation.

\section{References}

Epstein E 1972 Active ion transport in cells and tissues. In Mineral Nutrition of Plants: Principles and Perspectives. pp 103-150. John Wilcy and Sons. New York.

(ilass A D M and Dunlop J 1978 The influence of potassium content on the kinctics of potassium influx into excised ryegrass and barley roots. Planta $141,117-119$.

Ito O, Tobita S, Matsunaga R, Rao T P and Johansen ( 1992 Inorganic nitrogen in soil water collected from soil under intercrop components sorghum and pigeonpea - A pot experiment. In Proceedings of the International Symposium on Nutrient Management for Sustained Productivity. Vol 11. pp 16-18. Dept. of Soils, Punjab Agricultural University.

Johnson C M, Stout P R, Broyer T C and Carlton A B 1957 Comparative chlorine requirements of different species. Plant and Soil 8, 3.37-3.3.3.

Kochian L V and Lucas W J 1982 Potassium transport in corn 


\section{Ammonium and nitrate uptake in legumes and cereals}

roots. 1. Resolution of kinetics into a salturable and linear component. Plant Physiol. 70, 1723-1731.

Nandi S K and Pant R C 1984 Temperature effect on kinetics of phosphate uptake by excised corn (Zea mays L. var (ianga 5) roots. Ind. J. Exp. Biol. 22, 564-567.

Nissen P 1989 Multiphasic uptake of potassium by corn roots. No lincar component. Plant Physiol. 89, 231237.

Oaks A. Aslam M and Boesel I I. 1979 Influence of amino acids as regulators of nitrate reductase in corn roots. Plant Physiol. 59, 391-394.

Pace G M and McClure P R 1986 Comparison of nitrate uptake parameters across maize inbred lines. J. Plant Nutr. 9. 109.5-1111.

Pan W L, Jackson W A and Moll R II 1985 Nitrate uptake and partitioning by corn root systems. Differential effects of ammonium among genotypes and stages of root development. Plant Physiol. 77, 560-566.

Rato K P and Rains W 1976 Nitrate absorption by barley I. Kinetics and energetics. Plant Physiol. 57, 55-58.

Robinson D and Rorison I H 1983 Relationships between root morphology and nitrogen availability in a recent theoretical model describing nitrogen uptake from soil. Plant Cell Environ. 6. 641 - 647.

Siddiqi M Y, Glass A D M. Ruth T J and Rufty T W 1990 Studies of the uptake of nitrate in barley. I. Kinetics of ${ }^{13} \mathrm{NO}$; influx. Plant Physiol. 93, 1426-14.32.
Singh S P and Pant R C 1982 Kinetics of phosphate uptake in excised corn (Zea mays L. var Ganga 5) roots. Ind. J. Exp. Biol. 20, 324-326.

Valc F R, Jackson W A and Volk R 1987 Potassium influx into maize root systems: Influence of root potassium concentration and ambient ammonium. Plant Physiol. 84. 1416-1420.

Van de Dijk S J, Lanting L, Lambers $H$, Posthumus F, Stulen I and Hofstra R 1982 Kinctics of nitrate uptake by different species from nutrient-rich and nutrient-poor habitats as affected by the nutrient supply. Physiol. Plant. 55. $10.3-110$.

Wasnik K (i, Varade P B and Baggal A K 1988 Nitrate reductase activity in chickpea (('icer arietinum L.) leaves, roots and nodules in relation to moisture stress. Ind. J. Plant P'hysiol. 31, 324 327.

Yoneyamia T, Arima $Y$ and Kumazawa K 1975 Sample preparation from dilute ammonium solution for emission spectrographic analysis of heavy nitrogen. J. Sci. Soil Manure Jap. 46, 146-147.

Reprinted from Plant and Soil 154: 67-72, 1993. 